\title{
Construção da identidade profissional docente de estagiários em educação física
}

\author{
Construction of the teaching professional identity of trainees in physical education
}

\author{
Veruska Pires \\ Universidade Federal do Rio Grande do Sul, Brasil \\ veruskapires03@gmail.com
}

Gelcemar Oliveira Farias

Universidade do Estado de Santa Catarina, Brasil

Paula Maria Fazendeiro Batista

Faculdade de Desporto da Universidade do Porto, Brasil

\begin{abstract}
Resumo:
O objetivo do estudo foi analisar a construção da identidade profissional de estudantes estagiários em Educação Física, considerando as categorias estabelecidas por Dubar (1997), a partir das experiências vivenciadas nos tempos anteriores à formação inicial, na formação inicial e nos estágios curriculares. Participaram 59 estudantes de dois cursos de licenciatura em Educação Física de Florianópolis. As evidências revelaram que os tempos anteriores à formação inicial estão carregados de processos identitários biográficos a partir da identidade herdada. Na formação inicial, a identidade herdada perde seu espaço para uma identidade visada, mas com marcas da identidade social virtual. Os poucos ensaios sobre e na docência efetivados nos estágios garantem a configuração de uma identidade requerida, com base nos atos de atribuição e pertença. Conclui-se que a identidade docente individual é marcada pelas crises identitárias, originadas num tempo de descobertas e solicita uma identidade docente coletiva para se concretizar numa identidade social real.
\end{abstract}

Palavras-Chave: Educação Física, Formação de professores, Estágios curriculares, Identidade docente.

\begin{abstract}
:
The aim of the study was to analyze the professional identity construction of trainee students in Physical Education, considering the categories established by Dubar (1997) This was based on the experiences lived before the period of undergraduate, during the period of undergraduate, and during the curricular internships. The participants were 59 students from two undergraduate majors in Physical Education of Florianópolis. Evidence has shown that the time prior to the undergraduate period is loaded with biographical identity processes from inherited identity. During the undergraduate period, the inherited identity loses its space to a targeted identity, but with marks of the virtual social identity. The few essays on and in teaching done in the stages guarantee the configuration of a required identity, based on the acts of attribution and belonging. We conclude that the individual teacher identity is marked by the crises of identity, originated in a time of discovery and calls for a collective teaching identity to be realized in a real social identity.
\end{abstract}

KEYwords: Physical Education, Teacher training, School placement, Teaching identity.

\section{INTRODUÇAO}

Os estudos de Dubar (1997; 2003; 2005; 2006) discutem a identidade como um produto de comportamentos, características e atitudes incorporados pelos indivíduos a partir dos papéis assumidos 
em diferentes contextos, como a família, os amigos e os espaços profissionais. Já a identidade profissional, ao se configurar numa esfera específica de determinado campo de trabalho, está impregnada por identidades individuais, evidenciadas em atos de pertença (o que o indivíduo quer ser) que se unem, necessariamente, num processo coletivo, para concretizar as funções definidas pelas características e pelas exigências deste campo (Dubar, 2005; Alarcão, 2014). Ao se reportar especificamente à identidade docente, Dubar (1997) ressalta que a sua construção compreende um processo biográfico e relacional de reapropriação crítica das experiências vividas ao longo da vida. Tal processo tem início na infância e se prolonga nos anos passados no espaço escolar, num processo de interação com diferentes modos e crenças acerca do que é ser professor (Collay, 2006; Marcon, Graça \& Nascimento, 2010).

Partindo deste quadro, a formação inicial pode ser caracterizada como um dos contextos que marca o processo de construção da identidade profissional, pois o futuro profissional, mediante a qualificação recebida, estabelece relações, muda comportamentos e adquire os requisitos necessários para o exercício profissional. As categorias da identidade profissional, que segundo Dubar (1997) perpassam os tempos vividos pelos estagiários e que traduzem a compreensão do que é ser professor nos diferentes momentos da formação docente, compreendem os processos relacional e biográfico, a identidade do outro e para si, os atos de atribuição e de pertença, as identidades social-virtual e social-real, e as transações subjetivas e objetivas.

Um outro aspecto ressaltado por Dubar (2005) é que a identidade profissional compreende um conjunto de transações internas (subjetivasdo indivíduo) e externas que são mediadas entre os indivíduos e as instituições (relacionais). Enquanto que o processo biográfico da identidade é permeado pela identidade para si, o processo relacional ocorrido na construção da identidade é entendido como a identidade para o outro. Além disso, as observações e as interpretações do círculo social em que se inserem os indivíduos contêm aspectos influenciadores na identidade herdada ou visada, o que caracterizam os atos de atribuição e de pertença. Para tanto, o entendimento do que 'posso ser' ou 'quero ser' está relacionado ao que os outros 'querem de mim' (Dubar, 2005).

Ao compreender os processos relacionais e biográficos como estruturantes da identidade profissional, Dubar (1997) também reconhece que neles há situações pontuais e determinantes para que a identidade se reconfigure conforme incorporações entendidas e aceitas pelos indivíduos. Assim, a identidade profissional se molda entre os paralelos de uma identidade que o outro quer para mim e do que eu defino para mim próprio. Este movimento não é contraditório ou excludente, mas sim uma interlocução de dois prismas que se manifestam na configuração da identidade profissional em diferentes tempos vividos (Alarcão, 2014).

Outro aspecto não menos relevante apontado por Dubar (1997) é que há um desequilíbrio entre as identidades social, virtual e real. Em um primeiro momento, o que é recebido pelo outro (agentes ou instituições) parece ser mais significativo do que aquilo que é construído pelo próprio indivíduo. Porém, num segundo momento, a valorização das concepções construídas em tempos anteriores e das expectativas verídicas sobre e para a formação passa a ser colocada à prova, influenciando a incorporação de uma identidade profissional real (Dubar,1997). Flores e Day (2006) apontam também três fatores contextuais que influenciam a construção da identidade profissional do professor: as experiências prévias, a formação inicial e o impacto do contexto de trabalho (cultura escolar).

$\mathrm{Na}$ agenda investigativa que contempla as contribuições teóricas de Dubar destacam-se os estudos que referendam a identidade profissional docente sob a ótica dos supervisores de estágio e a escolha da profissão (Benites \& Souza Neto, 2011; Benites, Souza Neto, Borges, \& Cyrino 2012; Simões Neto \& Nascimento, 2018), das condições sociais do trabalho (Fortes, 2008), das aprendizagens e sentidos da profissão, e a carreira docente (Fraga, 2008; Farias, Batista, Garça \& Nascimento, 2018), as experiências prévias que influenciam na escolha pela profissão (Cardoso, Batista \& Graça, 2016) e ainda dos desafios das propostas de estágios curriculares (Iza \& Souza Neto, 2015). Contudo, acredita-se que uma perspectiva inversa de análise se faz necessária para interpretar a interlocução dos princípios da identidade profissional a partir dos registros 
biográficos de estudantes estagiários, na tentativa de melhor compreender como as experiências, os tempos, os espaços e os registros teórico-conceituais impactam na identidade do futuro professor de Educação Física.

Neste contexto de uma estrutura macro da identidade profissional, faz-se um recorte na constituição da identidade docente e, em específico, na formação de professores de Educação Física. Assim, o objetivo do estudo foi analisar a constituição da identidade profissional de estudantes estagiários em Educação Física, considerando as categorias estabelecidas por Dubar (1997), a partir das experiências vivenciadas nos tempos anteriores à formação inicial, na formação inicial e nos estágios curriculares.

O estudo se justifica pelas relações estabelecidas no conjunto das socializações de hábitos, tradições, habilidades e conhecimentos da Educação Física, que estão vinculados ao universo profissional vivenciado no estágio pelo futuro professor e também aos projetos políticos e culturais assimilados historicamente. Tais posturas expressam os valores e as representações sobre o corpo, o esporte, o papel de educação/escola/ organizações que impulsionam a reflexão sobre as identidades construídas (Rozengardt, 2006). Além disso, as identidades sociais herdadas (Padilha \& Nelson, 2011) e as expectativas acerca da docência, oriundas de processos de socialização antecipatória (Dubar, 1997), filtram as experiências da formação e as possibilidades de aprendizagem. Ressalta-se também que resquícios do tempo dos estágios curriculares são identificados durante toda carreira docente, ou seja, a identidade se constitui na auto análise de experiências significativas, que emanam da prática e da biografia do professor (Vloet, 2007). Esta biografia docente se configura nas experiências, nas histórias de vida, nos exemplos dos docentes durante a formação inicial e nas práticas desenvolvidas em espaços como os estágios obrigatórios e não obrigatórios (Formosinho, 2001).

\section{Metodologia}

O estudo descritivo, com abordagem qualitativa dos dados, foi realizado com estudantes que estavam regulamente matriculados nas disciplinas de estágios curriculares dos cursos de formação de professores de Educação Física de duas universidades públicas de Florianópolis (SC). Participaram voluntariamente da investigação 59 estudantes estagiários, sendo 19 da universidade A e 40 da universidade B.

$\mathrm{Na}$ recolha das informações foi utilizado, inicialmente, um questionário e aplicada, posteriormente, a técnica de grupo focal. $\mathrm{O}$ questionário, construído e validado para caracterizar os tempos e os lugares de vivencias de prática pedagógica e estágios de cada estudante investigado, foi composto por 26 questões fechadas e abertas, que contemplaram as dimensões: dados de identificação, ser professor, estágios curriculares, experiências anteriores a formação inicial e a formação inicial.

Para aprofundar a reflexão da identidade no tempo específico dos estágios curriculares, uma sessão de grupo focal foi realizada em cada instituição investigada com estudantes que apresentavam maior número de disciplinas cursadas e maior comprometimento com o curso, indicados pelos respectivos professores das disciplinas de estágio. Enquanto que cinco estagiárias e dois estagiárias participaram da reunião na universidade $\mathrm{A}$, na universidade $\mathrm{B}$ participaram quatro estagiárias e três estagiários.

O software QSR Nvivo, versão 9.0, foi utilizado para auxiliar na análise do conteúdo evidenciado nas falas dos estudantes investigados. Assim, foi possível estabelecer "os nós e sub nós" que fundamentaram as interpretações, sendo eles: tempo anterior a formação inicial (marcas positivas dos professores da escola básica; treinadores/professores de esportes/práticas corporais; relação com o esporte e diferentes atividades físicas; familiares e amigos); tempo da formação inicial (marcas relevantes positivas; frustrações; encantamentos e motivações pela e para a docência); e tempo dos Estágios Curriculares (experiências, prática pedagógica e contexto escolar, e identidade com subfatores, ideias, atribuições e relações).

As respostas dos questionários e as falas oriundas dos grupos focais foram transcritas e analisadas a partir das orientações de Benites, Nascimento, Milistetd \& Farias (2017). A transcrição das falas foi entregue a cada participante do grupo focal para validação das declarações (Negrine, 2004). A construção das categorias de análise voltou-se para a compreensão de como as afirmações e as vivencias relatadas pelos estudantes 
estagiários caracterizavam a construção de uma identidade. A partir deste movimento foi possível estabelecer relações com as categorias da identidade profissional de Dubar (1997), nomeadamente os processos relacional e biográfico, os atos de atribuição e de pertença, a identidade social-virtual e social real e as transições objetiva e subjetiva. A validade interpretativa das informações (Patton, 1990; Sparkes \& Smith, 2014) foi assegurada a partir do confronto e discussão de dois peritos com vasta experiência em investigação qualitativa sobre formação profissional em Educação Física.

\section{Resultados E Discussao}

\section{Tempo anterior a Formação Inicial}

Este momento é demarcado pela formação anterior ao ingresso dos estudantes estagiários na formação inicial, no qual os estudantes investigados evidenciaram a individualidade nos processos biográficos da identidade profissional. Neste tempo, os atos de pertença assumem características internas e o fundamento está naquilo que cada um querser, independente de influências externas. No entanto, as marcas biográficas constituídas a partir de crenças e de ideias são resignificadas nos e pelos atos de atribuição, resultando em "tatuagens" de uma identidade social real (Dubar, 2003; 2006).

Em relação às categorias da identidade profissional de Dubar, os relatos sobre o tempo anterior à formação inicial permitiram identificar algumas características das identidades herdadas e visadas, dos atos de pertença, das transações objetivas e subjetivas e da identidade social real. Estes atributos se revelaram por meio de marcas significativas sobre a figura dos professores da escola básica, das rotinas de práticas com esportes e outras manifestações corporais,

Os registros, que indicaram a presença de professores da escola básica na identidade biográfica dos estudantes estagiários, mencionavam estes profissionais a partir de lembranças afetivas e de suas práticas pedagógicas. Contudo, nem sempre as falas apontavam registros positivos e, como num processo de auto percepção, também resgatavam atitudes que eram rechaçadas pelo intuito inconsciente de uma mudança.

A dicotomia entre as experiências positivas e negativas no período anterior à formação inicial revelouse como base de sustentação para suas práticas docentes. Neste sentido, a materialização destes registros se tornou mais significativa pelo fato de terem sido experimentados pelos próprios estudantes. Além disso, o forte envolvimento pessoal está associado para uma "experiência de aprendizagem na ação", situação que favorece sínteses sobre a profissão e que muitas vezes é desconsiderada na organização dos currículos dos cursos de formação (Albuquerque, Pinheiro \& Batista, 2013, p.134). De fato, este é um momento propício para as primeiras crises identitárias, geradas pela tensão daquilo em que se acredita, com o que se espera e o que realmente se consegue ou se é capaz (Fraga, 2008; Dubar, 2012).

Um aspecto que também foi possível identificar é que, antes da escolha da profissão em Educação Física, os estudantes investigados estabeleciam relações com a prática rotineira de esportes e outras manifestações corporais ou somente o gosto e envolvimento pelas diferentes questões com o movimento. Estas experiências demarcam percursos individuais, únicos e singulares, contextualizados num grupo de pertencimento com semelhanças e aculturamento de ações e atitudes. De acordo com Borges e Desbiens (2005), estas vivências são fundamentais na Educação Física, pois orientam e moldam alguns saberes da profissão e, por consequência, facilitam a aproximação com os conteúdos da área.

Aqueles que vivenciaram de forma mais intensa os esportes e as práticas corporais traziam consigo marcas da figura do treinador, das rotinas diárias de treinamento, da participação em eventos, da exposição e da avaliação constante, entre outras ações efetivas destes contextos, que podem ser caracterizados como mentores dos estudantes estagiários (Brasil, Ramos, Barros, Godtsfriedt \& Nascimento, 2015). O sentimento de pertença, que influencia a definição de "que tipo de homem (ou de mulher) você é", se revela numa 
situação condicionada por um determinado período que, quando codificado, permite aos outros ou ao próprio indivíduo classificações de pertencimento ao grupo, categoria ou classe (Dubar, 1997, p.106).

Nestes casos específicos, as manifestações dos estudantes estagiários indicavam que eles tiveram contato e estiveram associados aos diferentes contextos de movimento ou práticas corporais, fato que os aproximavam de saberes que não estão vinculados a um reconhecimento pela prática, ou seja, pelo saber fazer. Esta característica alicerça aspectos intervenientes dos atos de pertença, onde o indivíduo se classifica como parte de um grupo por afinidade e por interesses, mas ainda não registra com efetividade como é ser e estar num coletivo profissional.

O movimento anterior e na própria formação inicial acontece em forma de transações. As transações subjetivas perfazem o caminho do que foi escolhido pelo indivíduo enquanto identidade e a relação com aquilo que pode ser prospectado como uma identidade (Lopes, 2007). A transação subjetiva está, por exemplo, no uso das aulas de dança vivenciadas em práticas pedagógicas durante os estágios curriculares. Figueiredo (2010) acredita que na tensão entre tais vivências e os saberes normativos encontram-se as mudanças identitárias. Contudo, estas alterações somente terão significado e força numa nova identidade profissional, se os cursos de formação inicial forem capazes de resgatar as memórias sócio esportivas num processo crítico reflexivo sobre as perspectivas atuais da Educação Física na escola (Almeida \&Fensterseifer, 2007).

Outro conceito importante discutido por Dubar (1997) é o da identidade social real, que é legítima ao indivíduo por ser percebida como possível. Durante o processo de formação profissional, algumas imagens idealizadas pelos estudantes definem determinadas atitudes a serem copiadas em suas práticas pedagógicas. Este dado foi destacado em um menor grupo de relatos dos investigados, os quais resgatavam as informações sobre familiares e amigos que eram professores de Educação Física e que, em suas rotinas, ilustravam representações externas e concretas sobre a docência.

\section{Tempo da Formação Inicial}

As marcas e os registros da formação inicial se configuram, prioritariamente, nas ações experimentadas ao longo do curso. Nesta fase, o processo relacional da identidade profissional se manifesta de forma mais contundente, já que a identidade para o outro é marcada pelas definições da proposta curricular e pedagógica do curso de formação inicial. Assim, os princípios políticos e filosóficos que fundamentam cada curso estabelecem, de determinada forma, os atos de atribuição, referendados em um grupo de pertencimento (Dubar, 1997; Lopes, 2007). Contudo, este tempo é marcado pelas transações objetivas, onde identidades atribuídas passam a ser assumidas num processo de conversões identitárias (Dubar, 2012).

A maior parte dos relatos sobre o tempo da formação inicial contempla as categorias dos atos de atribuição, transações objetivas, conversões identitárias, identidades sociais virtuais e convergência entre os atos de atribuição e pertença. Além disso, os dados do estudo se concentraram em marcas relevantes e positivas vivenciadas no curso, nas frustrações oriundas do processo de formação, nos momentos e espaços de encantamento e motivações pela e para a docência.

A relação intrínseca entre identidade e as características da área de atuação se imbricam naquilo que Dubar (2007) considera como indícios de atos de atribuição. Os atos de atribuição determinados socialmente passam a ser verdades contestadas ou não, mas reais no conjunto de normas e conhecimentos da profissão (Dubar, 2012). Os relatos dos estudantes estagiários, que contextualizavam as funções e formas de atuação, os conhecimentos e saberes necessários, as práticas pedagógicas, entre outros, exemplificam possíveis atos de atribuição.

Os estudantes estagiários também revelaram que tais atribuições estão associadas aos professores, nas disciplinas dos cursos de licenciatura investigados, e nas ações reflexivas sobre a formação para a docência. As ações ou sentimentos prospectados nos relatos tornam-se significativos a ponto de impactarem a constituição 
da identidade profissional, tornando-se relevantes marcas positivas da formação inicial. As disciplinas mostraram-se significativas, principalmente, pelas estratégias práticas de ensino, que por algumas vezes puderam ser aproveitadas nas aulas dos estágios.

O distanciamento da atividade real do professor na escola, segundo Fortes (2008), prospecta um mundo virtual sobre a docência. Este mundo virtual restringe as vivências sobre as escolas somente no interior de algumas disciplinas. Além disso, sem ter a possibilidade de um contraponto concreto sobre as funções de ser professor, aquilo que é atribuído pelo outro (entidades e ou agentes) para o indivíduo se manifesta como uma identidade social que, a princípio, passa a ser absorvida sem contestação pelo estudante em formação (Dubar, 1997).

Não obstante, ainda é na formação inicial que se depositam verdades sobre o que é necessário aprender para se tornar um professor (Pereira \& Figueiredo, 2018). Assim, aquilo que está introspectado, de forma inconsciente, dá lugar ao que é atribuído. Então, neste movimento surge a transação objetiva, que dinamiza as percepções individuais da docência numa perspectiva social para a identidade. As aspirações coletivas (identidade atribuída) se misturam aos anseios individuais (identidades assumidas) num processo de conversão identitária, resultando nas identidades sociais virtuais, isto é, o que eu quero ser/fazer está atrelado ao que querem de mim, impactado pelo o que eu posso querer e posso fazer (Dubar, 1997).

Um aspecto evidenciado pelos estudantes investigados é que a percepção de estar pronto para a intervenção profissional parece ser reforçada pela comparação com outras experiências vivenciadas, assim como a descoberta deste sentimento surge como novidade e motivação sobre a escolha profissional. De fato, a preparação para desenvolver as funções docentes está impregnada por aspectos incorporados nas informações externas, isto é, nos atos de atribuição (o que querem de mim). Quando a sensação de estar apto aflora, os atos de pertença passam a legitimar a profissão. Além disso, na convergência dos atos de atribuição e dos atos de pertença "que um indivíduo é conduzido a aceitar ou recusar as identificações que recebe dos outros ou das instituições” (Dubar, 1997, p.106).

Outro aspecto não menos relevante é que o entendimento do que é ser professor está assegurado nos primeiros ensaios sobre a docência, tanto na época de estudante da Educação Básica como nos princípios teóricos indicados durante a formação. Assim, a desconstrução das identidades herdadas durante a formação inicial deveria ser efetivada com base em experiências concretas. Os relatos dos estudantes investigados indicam que a identidade para si ganhou novos contornos, mas ela somente se revelou ainda num plano imaginário, já que as vivencias reais da escola e da docência foram superficiais. Assim, o delineamento inicial de uma identidade até o início das disciplinas de estágios curriculares se configurou num sentimento abstrato.

\section{Tempo dos estágios curriculares obrigatórios em Educação Física}

Os estudantes estagiários investigados relataram que o percurso da formação inicial foi marcado por dois momentos. Enquanto que no período que antecede as experiências do estágio, os atos de atribuição perfazem uma identidade que é construída por uma identidade relacional, os momentos de experimentação da docência no período dos estágios obrigatórios são impactados por uma identidade visada, pautada na virtualidade dos processos educativos.

A identidade visada, segundo Dubar (1997), corresponde ao processo de identificação do que quero e devo fazer profissionalmente, ainda com base numa identidade relacional. Este movimento é registrado pelas conversões identitárias onde uma nova identidade biográfica passa a ser delineada, porém influenciada diretamente nos processos externos da identidade. Esta instabilidade provavelmente poderá ser resignificada em crises identitárias, as quais exigem do professor mudanças que vão desde a forma de agir e os locais de prática, ou até mesmo de rumos profissionais (Lopes, 2003; 2007).

O descompasso entre a escola e a universidade, característica apontada pelos estudantes investigados sobre os respectivos cursos de formação, delimita a forma como a identidade profissional dos estudantes 
estagiários é configurada. Tal descompasso foi identificado nas discussões das disciplinas, nas fragilidades das ações extra disciplinas e na postura assumida pelos professores universitários. De acordo com Conceição e Dias (2012), esta realidade impacta no jogo de reconhecimento, onde o estudante necessita de informações claras e concretas sobre os contextos educativos, para definir estratégias de atuação e inserção. Embora tal reconhecimento não possa eliminar crises identitárias, ele ameniza impactos e frustrações que podem colocar em dúvida habilidades e competências para a docência (Lima, et al., 2014).

Os estágios curriculares compreendem importantes momentos de experiências refletidas, que devem também estabelecer espaços de ampliação de competências e não apenas de aplicação das habilidades necessárias do ser professor (Batista, Pereira \& Graça, 2012). Contudo, em ambos cursos de formação investigados, os estudantes estagiários identificam as atividades que devem ser desenvolvidas numa aula, mas não reconhecem o meio em que esta aula está inserida. De fato, um dos dilemas da formação de professores de Educação Física é a falta de contextualização do espaço real da escola, onde conceitos teóricos podem ser reconstruídos com fundamento numa realidade vivida (Scherer, 2008; Iza \& Souza Neto, 2015).

Outro aspecto a ressaltar é que a formação inicial auxilia na definição de uma versão da imagem do que é ser professor (Lopes, 2007). Contudo, quando esta imagem se estrutura a partir da superficialidade das informações reais da docência, ela estimula bloqueios que podem ser carregados por toda a carreira profissional. Assim, a identidade profissional individual surge nos estudantes investigados a partir das atribuições que são reconhecidas e requeridas para a profissão docente, mas que não foram vivenciadas pelos estudantes nos estágios.

A investigação realizada por Vieira, Vieira e Fernandes (2006) já apontava que a percepção sobre a docência está fortemente vinculada às escolhas didático-pedagógicas assumidas pelos estudantes estagiários, isto é, ao dar aulas. Não obstante, alguns estudos (Borges, 2008; Formosinho \& Niza, 2009) têm reforçado a ideia de que a formação inicial deve atentar para um universo muito mais complexo do que ensinar algo. Essa experimentação restrita sobre o que é a docência favorece a manifestação de uma identidade social virtual, onde o processo de transação objetiva é estimulado pelas identidades atribuídas e reconhecidas, mas não é concretizado a partir das identidades assumidas e incorporadas (Dubar, 2005).

Os professores supervisores aparecem frequentemente nos relatos dos estudantes investigados como exemplos a serem seguidos ou então rechaçados. Apesar das críticas positivas e de fragilidades dos professores supervisores nunca serem desconsideradas nas observações estabelecidas pelos estagiários (Rozengardt, 2006), é na figura do professor supervisor que a realidade da prática pedagógica da escola se manifesta (Batista; 2011; Benites et al., 2012; Resende et al., 2014). As ações oriundas de atividades realizadas nas disciplinas do curso de formação de professores também aparecem nos relatos, mas não são reconhecidas de imediato pelos estudantes investigados como necessárias na atuação docente. Este movimento marca um processo de transição de identidades, ou até mesmo confirmação, pois até então os estudantes estão construindo um entendimento próprio da docência, mas que certamente precisa ser testado para ser incorporado (Ronfeldt \& Grossman, 2008; Feldkercher, 2010).

Esta característica transitória da identidade pode ser perigosa, pois ela se manifesta pelo sentimento de insegurança e de incapacidade, especialmente por não se configurar num momento de testagem e reflexão. Caso os estudantes tivessem experimentado as ações de docência antes do estágio, os erros e acertos já teriam sido analisados num processo de ação, reflexão e ação. Assim, o estágio curricular compreenderia um espaço real de treinamento para a docência e não um espaço de apresentação e reconhecimento do que é ser professor (Lopes, 2007; Batista, 2011; Lima et al., 2014). De modo geral, os indícios de uma identidade profissional vão confirmando a opção que começou a ser delineada muito antes do ingresso nos estágios, porque aquilo que é ratificado nos estágios parece ter sua origem ainda no papel de estudante, onde exemplos são incorporados sem a percepção de um possível impacto numa atuação docente (Tardif, 2010). A linearidade do processo não estimula contradições, mas as crises mobilizam reflexões que promovem as mudanças identitárias (Batista et al., 2012) 


\section{Consideraçoes finais}

O presente estudo demarcou as categorias de identidade profissional de Dubar (1997), que são reveladas nos tempos anteriores a formação inicial, na formação inicial e nos estágios curriculares em Educação Física. Além disso, as evidências permitiram concluir que a identidade docente dos estudantes estagiários é constituída a partir das relações, especialmente com os supervisores e orientadores, das atribuições vivenciadas nos atos de ensino e aquelas requeridas nos atos profissionais, assim como dos ideais de mudança na educação.

Nos tempos anteriores a formação inicial, as atividades corporais, os treinadores e a influencia dos familiares são importantes na constituição da identidade, cujos registros biográficos se tornam relevantes na formação do professor e deveriam ganhar mais destaque no processo formativo. Além da identidade profissional estar carregada de processos identitários biográficos a partir de uma identidade herdada, a quebra ou reconstrução destes registros simboliza transações da identidade, ora num processo de afirmação, ora numa negação de verdades já estabelecidas.

No tempo da formação inicial em Educação Física, as evidencias revelam que as atribuições estão associadas aos professores nas disciplinas e às ações reflexivas sobre a formação para a docência. Independentemente dos problemas elencados sobre os cursos investigados, os relatos indicam que o sentimento de encantamento para a docência se cristaliza na aptidão para os atos do ensino, nas preferências de níveis de ensino para atuação, na continuidade dos estudos e nos possíveis cenários de trabalho. Entretanto, os poucos ensaios sobre e na docência, efetivados durante a formação inicial, garantem a configuração de uma identidade requerida, concretizada sob os atos de atribuição e pertença. Ressalta-se que a identidade herdada perde seu espaço para uma identidade visada, mas com marcas de uma identidade social virtual.

A construção da identidade no tempo de estágio curricular compreende um processo continuo de reflexões e experiências, cuja dinâmica parece estabelecer verdades sem muita sustentação concreta na realidade do contexto educativo. Assim, quando os objetivos dos estágios são atingidos, a profissão docente passa a ter sentido e até as limitações do próprio curso e as dificuldades dos estágios são amenizadas. Num tempo de descobertas, a identidade docente individual é marcada pelas crises identitárias, bem como assume características de uma nova identidade biográfica, a qual solicita uma identidade docente relacional para se concretizar numa identidade social real.

Ao revelarem um cenário construído com fortes indicativos do que é a docência, porém fundamentado numa superficialidade de vivências do real e atual da escola e do estudante, as evidências encontradas permitem recomendar o desenvolvimento de ações nos cursos de formação inicial em Educação Física que favoreçam a imersão dos estudantes, futuros professores, nas escolas desde as fases iniciais. Além da ampliação das atribuições e tarefas do estágio para permitir a vivência e o reconhecimento dos atos profissionais, recomenda-se que as discussões nas disciplinas favoreçam a construção e a reconstrução de conceitos pautados na realidade didático-pedagógica dos professores e na cultura docente atual das escolas.

\section{REFERENCIAS}

Alarcão, I. (2014). Desenvolvimento profissional, interação colaborativa e supervisão. In: Machado, J. \& Alves, J. M. (Ed.) Políticas de governação e liderança das escolas (pp. 22-33.). Coleção e-book. PortoUniversidade Católica Editora.

Albuquerque, A. A., Pinheiro, C. M., \& Batista, P. F. (2013). Crenças e concepções de estudantes de educação física ao longo da formação inicial: estudo nos setores público e privado em Portugal. Conexóes: Educação Física, Esporte e Saúde, 11(2), 127-147.

Almeida, L., \& Fensterseifer, P. E. (2007). Professoras de Educação Física: duas histórias, um só destino. Movimento, 13(2), 13-3. Acesso em: https://www.seer.ufrgs.br/Movimento/article/view/3542/1945 
Batista, P. M. F., Pereira, A. L., e Graça, A. B. S. (2012). A (re)configuração da identidade profissional no espaço formativo do estágio profissional. In: Nascimento, J. V.; Farias, G. O. (Eds.). Construção da identidade profissional em Educação Física: da formação à intervenção (pp. 81-112). Florianópolis: Ed. da UDESC.

Batista, P. (2011). Modelação da competência: desafios que se colocam ao estágio profissional. A. Albuquerque, C. Pinheiro, L. Santiago \& N. Nunes (Eds.), Educação física, desporto e lazer: perspectivas luso-brasileiras/ $3^{\circ}$ Encontro Educação Física, Desporto e Lazer, 429-442. Maia: Edições ISMAI

Benites, L. C., do Nascimento, J. V., Milistetd, M.,\& Farias, G. O. (2017). Análise de conteúdo na investigação pedagógica em educação física: estudo sobre estágio curricular supervisionado. Movimento, 22(1), 35-50.DOI: https://doi.org/10.22456/1982-8918.53390

Benites, L. C., de Souza Neto, S., Borges, C., \& Cyrino, M. (2012). Qual o papel do professor-colaborador no contexto do estágio curricular supervisionado na Educação Física? Revista Brasileira de Ciência e Movimento, 20(4), 13-25.DOI: http://dx.doi.org/10.18511/rbcm.v20i4.3286

Benites, L. C., \& Souza Neto, S. (2011). Educação física, professores e estudantes: a escolha da docência como profissão e os saberes que lhe são constitutivos. Pensar a Prática, 14(2).DOI: https://doi.org/10.5216/rpp.v14i2.12111

Borges, C. (2008). A formação docente em Educação Física em Quebec: saberes, espaços, culturas e agentes. In: Traversini, C. et al. (Eds.). Trajetória e processos de ensinar e aprender: práticas e didáticas. (pp. 147-174). Porto Alegre: EDIPUCSRS.

Borges, C. M. F.,\& Desbiens, J. (2005). Saber, formar e intervir para uma Educação Física em mudança. Campinas: Autores Associados.

Brasil, V. Z., Ramos, V., de Barros, T. E. D. S., Godtsfriedt, J., \& do Nascimento, J. V. (2015). A trajetória de vida do treinador esportivo: as situaçóes de aprendizagem em contexto informal. Movimento, 21(3), 815-829.DOI: htt ps://doi.org/10.22456/1982-8918.50773

Cardoso, M. I., Batista, P.,\& Graça, A. (2016). A identidade do professor de Educação Física: Um processo simultaneamente biográfico e relacional. Movimento, 22(2), 523-538.DOI: https://doi.org/10.22456/1982-89 18.54129

Collay, M. (2006). Discerning professional identity and becoming bold, socially responsible teacher-leaders. Educational Leadership and Administration: Teaching and Program Development, 18, 131-146. https://files.er ic.ed.gov/fulltext/EJ795116.pdf

Conceição, J. P., \& Dias, M. D. F. S. (2012). No jogo do reconhecimento: estágio supervisionado e identidade docente na formação de professores de História. EntreVer-Revista das Licenciaturas, 2(2), 110-123.

Dubar, C. (2007). Os “ensinamentos” dos enfoques sociológicos da delinquência juvenil. In: Paiva, V.\&Sento-Sé, J. T. (Eds.). Juventude em conflito com a lei. (pp. 157-180). Rio de Janeiro: Garamond.

Dubar, C. (1997). A socialização. Porto: Porto Editora.

Dubar, C. (2005). A socialização: construção das identidades sociais e profissionais. São Paulo: Martins Fontes.

Dubar, C. (2003). Formação, trabalho e identidades profissionais. In: Canario, R. (Ed.). Formação e situações de trabalho (pp. 43-52). Porto: Porto Editora.

Dubar, C. (2012). A construção de si pela atividade de trabalho: a socialização profissional. Cadernos de pesquisa, 42(146), 351-367.DOI: http://dx.doi.org/10.1590/S0100-15742012000200003.

Dubar, C. (2006). A crise das identidades: a interpretação de uma mutação. Porto: Ediçóes Afrontamento.

Farias, G. O., Batista, P. M. F., Graça, A., \& do Nascimento, J. V. (2018). Ciclos da trajetória profissional na carreira docente em educação física. Movimento (ESEFID/UFRGS), 24(2), 441-454.DOI: https://doi.org/10.22456/1 982-8918.75045

Feldkercher, N. (2010). O estágio curricular supervisionado como componente teórico e prático em cursos de formação inicial de professores. Revista Espaço Acadêmico, 10(115), 110-116. http://periodicos.uem.br/ojs/ind ex.php/EspacoAcademico/article/view/10862 
Figueiredo, Z. C. C. (2010). Experiências profissionais, identidades e formação docente em educação física. Revista Portuguesa de Educação,23(2), 153-171. http://www.scielo.mec.pt/scielo.php?script=sci_arttext\&pid=S0871$91872010000200007 \& \operatorname{lng}=$ pt\&nrm=iso

Flores, M. A., \& Day, C. (2006). Contexts which shape and reshape new teachers' identities: A multi-perspective study. Teaching and teacher education, 22(2), 219-232.DOI: https://doi.org/10.1016/j.tate.2005.09.002

Formosinho, J. (2001). A formação prática dos professores: da prática docente na instituição de formação à prática pedagógica nas escolas. Revista Portuguesa de Formação de Professores, 1(37-54).

Formosinho, J., \& Niza, S. (2009). Iniciação à prática profissional de formação inicial de professores.In: Formosinho, João (Org.). Formação de professores. (pp. 119-139). Porto: Porto Editora.

Fortes, V. M. R. (2008). A constituição da identidade do professor caboverdiano nas relações sociais e de trabalho. 213f. (Tese Doutorado). Centro de Educação, Pontifícia Universidade católica de São Paulo, São Paulo.

Fraga, R. D. (2008). Os/As professores/as de Educação Física e sua condição docente: aprendizagens e sentidos da profissão. 199f. (Dissertação Mestrado). Centro de Educação Física e Desportos, Universidade Federal do Espírito Santo, Espírito Santo.

Iza, D. F. V., \& de Souza Neto, S. (2015). Os desafios do estágio curricular supervisionado em educação física na parceria entre universidade e escola. Movimento, 21(1), 111-123.

Lima, R., Cardoso, S., Resende, R., Albuquerque, A., Castro, J., Pimenta, N. (2014). Formação inicial de professores de Educação Física: a perspectiva dos estudantes estagiários. In: Rolim, R.; Batista, P.,\&Queiròs, P. (Eds.) Formação inicial de professores: reflexão e investigação da prática profissional. Porto: Editora FADEUP.

Lopes, A. (2007). A identidade dos professores portugueses do $1^{\circ}$ CEB entre o passado e o futuro. In: Leite, C.,\& Lopes, A. (Eds.). Escola, curriculo e formação de identidades (pp. 173-192). Porto: Edições ASA.

Marcon, D.,\& Graça, A. B. D.S., do Nascimento, J. V. (2010). Estruturantes da base de conhecimentos para o ensino de estudantes-professores de Educação Física. (pp. 776-787). Motriz.Journal of Physical Education, 16(3), 776-787. DOI: https://dx.doi.org/10.5016/1980-6574.2010v16n3p776

Negrine, A. (2004). Instrumentos de coleta de informações na pesquisa qualitativa. In: Molina Neto, V.,\&Triviños, A. S. (Orgs.). A pesquisa qualitativa na Educação Física: alternativas metodológicas (p. 61-94). Porto Alegre: Ed. Universidade/UFRGS/Sulina.

Simões Neto, J. D. C., \& do Nascimento, R. M. (2018). O papel do professor-colaborador no contexto do estágio supervisionado em educação física: uma análise da produção científica. Revista Interdisciplinar Encontro das Ciências-RIEC, 1(2), 245-257. http://www.ojs.ufpi.br/index.php/rics/issue/view/440

Padilha, M. I.,\&Nelson, S. (2011). Networks of Identity: The Potential of Biographical Studies for Teaching Nursing Identity. Nursing History Review,19(1), 183-193. Recuperado de: https://www.ncbi.nlm.nih.gov/pubmed/21 329157

Pereira, G. D. S., \& Figueiredo, Z. C. C. (2018). O tornar-se professor de Educação Física na formação inicial: um olhar sob as narrativas de formação. Motrivivência, 30(56), 62-75. DOI: https://doi.org/10.5007/2175-8042. 2018v30n56p62

Patton, M.Q. (1990) Qualitative evaluation and research methods. 2. ed. Newbury Park: Sage.

Resende, R., Carvalho, M., Silva, E., Albuquerque, A., Lima, R., \& Castro, J. (2014). Identidade profissional docente: Influência do conhecimento profissional. In P. Queirós, P. Batista, \& R. Rolim (Eds.), Formação inicial de professores: Reflexão e investigação da prática profissional (pp. 145-164). Porto: Editora FADEUP.

Ronfeldt, M., \& Grossman, P. (2008). Becoming a professional: Experimenting with possible selves in professional preparation. Teacher Education Quarterly, 35(3), 41-60. Recuperado de: https://files.eric.ed.gov/fulltext/EJ83 1708.pdf

Rozengardt, R. (2006). Pensar las prácticas de formación de profesores en Educación Física. Educación Física y deporte, 25(2), 81-92. Recuperado de: http://aprendeenlinea.udea.edu.co/revistas/index.php/educacionfisicaydeporte/ article/view/3093 
Scherer, A. (2008). O desafio da mudança na formação inicial de professores: o estágio curricular no curso de licenciatura em Educação Física. 2008. 211f. (Tese Doutorado) - Faculdade de Educação, Universidade Federal do Rio Grande do Sul, Porto Alegre.

Sparkes, A., \& Smith, B. (2014). Qualitative research methods in sport, exercisa and health: from process to product. London: Routledge.

Tardif, M. (2010). Saberes docentes e atuação profissional. Rio de Janeiro: Vozes.

Vieira, L. F., Vieira, J. L. L., \& Fernandes, R. (2006). Competência profissional percebida: um estudo com estudantes de educação física em formação inicial. Journal of Physical Education, 17(1), 95-105.Recuperado de: http://ww w.periodicos.uem.br/ojs/index.php/RevEducFis/article/view/3375

Vloet, K. (2007). Career learning and teachers' professional identity: narratives in dialogue. In: Variations in the conditions for teachers' professional learning and development: sustaining commitment and effectiveness over a career. Oxford Review of Education., 33(4), 69-84. 